duals and between populations, and also reflect the migrations of identifiable human groups that kept acquiring differences and then re-stirring the genetic pot. The biochemistry does not entail genetic determinism. Lewontin stresses the plasticity of the human endowment, and the interaction of genotype and environment in producing adult variations. "The heritability of MN blood type is $100 \%$, and the heritability of the ability to pronounce rue like a Frenchman is zero". Human Diversity is a book that non-biologists will have to read carefully, because of a spattering of jargon and the subtleties of the subject, but the effort will be well rewarded.

While Lewontin's takes pride of place on my shelf as arguably the most important book of the five, it is Pierce's that finishes up at my bedside - also on my record player, because two disks come with The Science of Musical Sound. This is a personal and practical exploration of the subject by a distinguished electronics engineer who, besides being a pioneer of computergenerated music, also writes science fiction as J.J. Coupling. From a deceptively elementary start with the behaviour of stretched strings, the reader soon finds himself among the paradoxes and illusions that flower in the no man's land between physics, perception and art. Whether Pierce is dealing with scales, harmony, loudness or timbre, or with misadventures in architectural acoustics, he combines a lucid and lively presentation of the facts with shrewd discussion of the mysteries. His message is that the computer transcends all the limitations of previous musical instruments and offers many novel effects; these await only the supply of new genius that is not overpowered by the genius of the past. Although The Science of Musical Sound is entirely different in content and style from Powers of Ten, which I mentioned at the outset, they share an enthusiasm and delight which are muted in the other books.

From this batch of books, what should we conclude about the merits and problems of series-like publication of science for a general readership? The authors all have star quality, but inevitably they appear with variable magnitudes in this constellation. My guess is that the best of the books (Smoluchowski, Lewontin and Pierce) would have appeared willy nilly, from authors already full of their ideas. If the Scientific American Library is to take welldeserved credit for giving them a ride in its gleaming vehicle, then equally a question hangs over others that have an air of coming aboard to oblige the driver. These, I must stress, are in the minority. Quality control in the production of popular science, as with all books, is nevertheless a matter of making quite sure that every author has a fresh and exciting story to tell.

Nigel Calder is a science writer. His most recent book is Timescale: An Atlas of the Fourth Dimension (Chatto \& Windus, 1984).

\section{Grand organization in mind}

\section{Stuart Sutherland}

Frames of Mind: The Theory of Multiple

Intelligences.

By Howard Gardner.

William Heinemann/Basic Books: 1984. Pp. 438. $118, \$ 23.50$.

UNTIL about forty years ago, the fashionable psychologist rose to fame by proposing majestic theories that were une grande mélange de tout. William James, Ivan Pavlov, J. B. Watson and the Gestalt psychologists took the whole of human behaviour into their purview. The last in this romantic line was Donald Hebb: I remember the excitement generated in 1949 by the publication of his book, The Organisation of Behaviour - a typically modest title. Unfortunately, most of the theorizing in such books was as vague as the scope was broad, and psychologists came to work in more restricted domains. They felt it better to provide rigorous explanations for such fascinating phenomena as the movement evinced by a stationary point of light in a dark room or the faster learning of nonsense syllables at the beginning and end of a serial list than of those in the middle. Now, after a gap of 35 years, Howard Gardner has reverted to the grand tradition. No one can challenge the scope of Frames of Mind: it remains only to debate its rigour.

Gardner puts forward a faculty psychology. The idea that the human mind contains discrete and autonomous faculties is of course not new. It gave rise to phrenology and was subsequently defended by such practitioners of mental testing as L.L. Thurstone and J.P. Guilford. They attempted to uncover the different faculties by giving subjects an array of tests and performing a factor analysis on the results in order to extract a small number of hypothetical factors that would account for the correlations between the individual tests. As Gardner rightly points out, the enterprise foundered because there is no one solution to a factor analysis and because the tests given were arbitrary.

Gardner's originality lies in the composition of the seven faculties into which he claims human intelligence can be divided, and in proposing seven "unmistakable marks, by which you may know, wheresoever you go, the warranted, genuine" faculty. He describes his faculties as "intelligencies", but I shall keep to the oldfashioned word "faculty" since intelligence is not a count noun and to use it as one is a mockery of Gardner's first faculty, that for language. The other faculties he proposes are musical, logical-mathematical, spatial, bodily-kinaesthetic, and intraand extrapersonal. Spatial ability is the capacity to manipulate the world in the imagination: it is required for map- reading, for much of science, and for all painting; bodily-kinaesthetic ability is required both for moving the body and for manipulating the external world and is, according to Gardner, a prerequisite for dancers and inventors. The intrapersonal faculty is used to understand oneself, while the interpersonal one is for understanding others: Gardner seems in some doubt whether to classify these as two separate faculties or as different aspects of the same one.

Some may feel a sneaking suspicion that Gardner chose his seven faculties through common sense and then looked for supporting evidence by the use of his criteria, but that is a perfectly legitimate way to proceed. The criteria he has devised are as follows. First, each faculty should depend on a set of core operations that differ from one faculty to another. Many of the computations needed to use or understand language are clearly different from those needed by the spatial or bodily-kinaesthetic faculties. To understand language, however, it is surely necessary to make use of all the remaining faculties (though which is needed at any instant will depend on the topic of discourse), a point which Gardner does not adequately consider. Second, the existence of a particular faculty may be inferred if there are brain lesions that damage its operation while leaving the others unimpaired: showing that the computations underlying each proposed faculty are carried out in different parts of the brain is presumptive evidence that the computations themselves are different. This criterion works moderately well for most of the faculties, but it seems doubtful if personal intelligence can be impaired by brain damage without deterioration in many of the others.

A third and novel criterion is the existence of a heightened form of a single faculty in idiots savants, whose other abilities are severely impaired. They may attempt to compensate for a general loss in intelligence by developing to their utmost any faculty that has been spared. Some idiots savants have shown remarkable ability at such tasks as calculating the day of the week on which a particular calendar date falls, though it should be noted that none have become great or even good mathematicians. It is in fact open to question whether rapid calculations and real mathematical ability have much to do with one another.

Among the other criteria that Gardner uses are a distinctive evolutionary and developmental history for a given faculty. Neither of these is very compelling. We know little about the evolutionary history of most of the faculties he identifies, and it may be that in the individual the development of one faculty is tied to progress in another: thus, a child can hardly begin to enumerate objects (logical-mathematical) before having the concept of an object (spatial) and without some spatial knowlege it could not display much in the way of 
manipulative (bodily-kinaesthetic) skills.

Gardner further proposes that it should be possible to encode the operation of any faculty in a symbol system. This criterion is in part empty since almost all conscious thought processes can be so encoded. However, one of Gardner's faculties, bodilykinaesthetic, is very difficult to encode as anyone who has attempted to teach golf to beginners well knows. Moreover, it is extremely difficult to encode unconscious aspects of other faculties, for example, syntax, and Gardner's use of this criterion is obscure.

His final criterion is that there should be more correlation between the results of tests that depend on the same faculty than between those that depend on different ones. This appears to be true of tests of linguistic and spatial skill, and although Gardner does not mention it, it is also true of tests of bodily ability. Less favourable to Gardner's thesis is the fact that whenever a battery of tests is given, the results on all tests tend to correlate with one another (with the possible exception of tests of body skill). It is of course precisely on these correlations that the notion of general intelligence (or $g$ as Charles Spearman called it) is founded. Gardner does little or nothing to explain why, if the different faculties are completely independent, there should be such a high correlation between tests that ostensibly draw on several of them.

I have already noted that the development of the faculties may not be independent and that more than one may be used in the same task. The latter point Gardner himself acknowledges, but he fails to draw an important conclusion. In order to integrate the results of computations performed by two or more faculties, there must be some further computational mechanism at work that lies outside the individual faculties. Gardner decries the need for such a "horizontal" mechanism, but does not consider the question carefully enough. In the extreme case, the system could break down because one faculty was waiting on an input from a second in order to do further computation, while the second was waiting for an input from the first. For the same reason, Gardner's treatment of metaphor is weak: how could one faculty take as a metaphor something drawn from another unless it had a knowledge of how the other worked? A further argument that there is a superordinate mechanism to coordinate the knowledge processed in each of the faculties may be drawn from the effects of frontal lobe lesions, which often severely impair the ability to plan: this impairment is not limited to any one of Gardner's seven faculties.

If Gardner is weak on the horizontal organization of the mind, he is even weaker on its vertical organization. By almost all of the criteria he lists, vision and audition should be special faculties though much of their output is fed to other faculties (for

example, audition makes possible both language and music). Again, it is well known that anterograde amnesia can be produced in all domains by damage to the hippocampus. Even if memory is not a horizontal ability, this finding suggest that the different faculties share some common mechanism for the laying down of new memories.

One can also ask whether Gardner has cut his faculty cake correctly. It is in fact not easy to think of tasks whose performance cannot be accounted for by knowledge embedded in his seven faculties, but this is partly because several may be employed in the same task. Nevertheless, one could ask in which faculty resides a winetaster's skill or even the ability to discriminate sounds that are neither verbal nor musical.

Despite the interest of Gardner's general thesis, his book has several annoying de-

Trick of perception

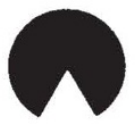

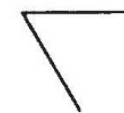
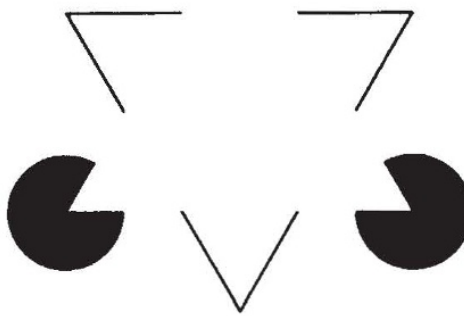

In this diagram the eye sees contours that are not present (illusory contours), and the figure so defined seems whiter than the surrounding area. The illustration is taken from lrvin Rock's Perception, a volume in the Scientific American Library. See footnote on p.791 for publication details.

fects. The worst is a trait that he shares with his predecessors in the grand tradition vagueness. Nowhere does he try to characterize in rigorous terms the operations carried out by the different faculties. Indeed, he decries computer simulations (which are the only rigorous theories of mental activities yet constructed), largely on the grounds that they are not biological. If he examines the work of David Marr and others, he will find that computer models can take into account neurophysiological findings. There are other passages where he is alarmingly naive: for example, he avers that work demonstrating the existence of cells that respond selectively to complex objects, like a hand or a face, has thrown much light on object recognition. Such research has not in fact illuminated this problem, since to understand how an object is recognized we would need to know how the cell is wired-up. He also has a habit of ducking difficult issues: he writes, for example, "The philosophical ambiguity that surrounds the concept of mental imagery can also be left to the experts"'.
Gardner is an enthusiast, who, like the Beaver, goes "bounding along on the tip of his tail". He is extremely discursive, a trait that will please anyone wanting a superficial romp through science, music, painting, architecture, dancing, baseball and so on, but that may well dismay anyone interested in rigorous arguments and upset anyone with much knowledge of the topics covered. His surveys too of ten lead him to such unremarkable conclusions as "One cannot aspire to be a poet without sensitivity to the interaction among linguistic connotations", "painting and sculpture involve an exquisite sensitivity to the visual world as well as an ability to recreate it in fashioning a work of art", or "certain features typically characterize the baseball player . . . there is . . . the ability to throw the ball where one wants it". It is perhaps no accident that in discussing science, Gardner fails to mention that one of its main attributes is the rigour with which its theories are expressed. His book also contains potted accounts of such figures as Von Neumann, Einstein and Rubinstein, and lengthy excursions into anthropology to illustrate how the different faculties are exhibited in different cultures. It ends with a lengthy section in which Gardner attempts to apply his notion of faculties to education. Much the most interesting part is an account of the Suzuki method of musical education developed in Japan. Infants are trained almost from birth, and can often play violin concerti faultlessly by seven years of age. But Gardner's own recommendations are as vague as those of most other educationalists. "Early assessment . . . allows an individual to proceed as rapidly as seems warranted in those intellectual channels where he is talented, even as it affords an opportunity to bolster those intellectual endowments that seem relatively modest".

Gardner is a polymath, who has clearly developed all seven faculties, though as the quotations from his book suggest, his linguistic faculty could, in his own words, do with bolstering. His main thesis is interesting, but it is a pity he did not cut the trimmings, many of which are banal, and concentrate on working it out in more detail. In particular, he might have attempted to characterize more carefully some of the operations conducted in each domain, to give a more detailed and careful account of the horizontal interactions between faculties, and to deal more thoroughly with perception, memory and planning. Too often he prefers to leave the hard work to someone else. One suspects that once we know what are the computations performed by the mind and how the requisite software comes into existence, it will become clear that human faculties are much more blurred than he would have us believe or even that they are as elusive as the Snark itself. $\square$

Stuart Sutherland is Director of the Centre for Research on Perception and Cognition, University of Sussex. 